\title{
UM ESTUDO DAS POTENCIALIDADES DO ENSINO-APRENDIZAGEM DE MATEMÁTICA MEDIADO PELAS TECNOLOGIAS DE INFORMAÇÃO E COMUNICAÇÃO ${ }^{1}$
}

\author{
Daiane Kipper ${ }^{2}$ \\ Fabiane Sarmento Oliveira Fruet ${ }^{3}$ \\ Éder Julio Kinast ${ }^{4}$
}

\section{Resumo}

Neste trabalho, os professores de Matemática da Escola Estadual de Ensino Médio Nossa Senhora do Rosário, situada em Santa Cruz do Sul-RS, foram investigados se e como estão utilizando as tecnologias da informação e da comunicação (TIC) em seu fazer pedagógico nas séries finais do ensino fundamental e também se há uma formação inicial ou continuada desses docentes em relação às TIC na educação. Primeiramente, foi realizado um levantamento bibliográfico referente à integração das TIC no ensino-aprendizagem, especialmente, da Matemática. A segunda parte deste estudo se deu por meio da visitação a essa instituição, como também através de entrevistas semiabertas com os professores pesquisados, a fim de constatar os métodos adotados pelos professores de Matemática para a integração das TIC nas aulas de Matemática e a sua atualização para o uso das mesmas. Ao realizar a pesquisa, percebeu-se que apenas um dos docentes pesquisados utiliza as TIC, para potencializar o ensino da Matemática, como também busca a atualização para o uso das mesmas. A partir desses dados, constatou-se a necessidade da atualização dos professores das

\footnotetext{
${ }^{1}$ Artigo elaborado para conclusão do Curso Mídias na Educação, orientado pelos professores, Fabiane Sarmento Oliveira Fruet - UFpel e Éder Julio Kinast - UERGS.

${ }^{2}$ Mestranda em Educação, pela Universidade de Santa Cruz do Sul (UNISC). Bolsista da Coordenação de Aperfeiçoamento de Pessoal de Nível Superior (CAPES). Especialista em Mídias na Educação pela Universidade Federal de Santa Maria (UFSM) e Professora de Matemática da Municipal de Santa Cruz do Sul e da Rede Estadual do Rio Grande do Sul. End. Rua Prof. José Soder, 120 Santa Cruz do Sul - RS, Brasil - CEP. 96815.390 - Fone Fone: (51) 37172282/95632289. daianekipper@ hotmail.com

${ }^{3}$ Professora Orientadora, Mestre em Educação pela Universidade Federal de Santa Maria (UFSM). End. Rua Gomes Carneiro, 1· Centro - CEP 96010-610 - Pelotas, RS Brasil, Fone: (53) 3921-1401, fabysoliveira@gmail.com

${ }^{4}$ Doutor em Ciências - Física Experimental pela Universidade Federal do Rio Grande do Sul (UFRGS)e Professor adjunto da Universidade Estadual do Rio Grande do Sul. End. Rua 7 de Setembro, 1156, Centro, CEP: 90010-191 - Porto Alegre, RS - Brasil. Telefone: (51) 32889094, eder-kinast@uergs.edu.br.
} 
UM ESTUDO DAS POTENCIALIDADES DO ENSINO-APRENDIZAGEM DE MATEMÁTICA MEDIADO PELAS TECNOLOGIAS DE INFORMAÇÃO E COMUNICAÇÃO

séries finais do ensino fundamental para a utilização das TIC no ensino da Matemática, pois a escola possui recursos adequados para um ensino mediado pelas tecnologias. Nesse sentido, é necessário buscar em conjunto com a gestão, um planejamento pedagógico voltado para o uso das TIC na prática docente.

Palavras-Chave: Tecnologias de Informação e Comunicação; Ensino-aprendizagem; Matemática

\section{INTRODUÇÃO}

As mudanças, nos processos de ensino, vão tornando-se necessárias, devido aos baixos índices de aprendizagem e o desinteresse apresentados pelos alunos em relação à escola. Segundo os Parâmetros Curriculares Nacionais PCN (BRASIL, 1997a), o quadro educacional brasileiro é ainda bastante insatisfatório, pois alguns indicadores quantitativos e qualitativos apresentam o Brasil em comparação com outros países, em desvantagem na área da educação. $\mathrm{Na}$ década de 90, surgem várias propostas por parte do Ministério da Educação e das Secretarias de Educação, objetivando mudanças no processo educacional, sendo uma delas os PCN, que traz uma proposta de um ensino mais crítico e mais próximo da realidade dos alunos, dentro das especificidades de cada contexto.

Conforme os PCN (BRASIL, 1997a), é consensual a ideia de que não existe um caminho que possa ser identificado como único e melhor para o ensino de qualquer disciplina. Sendo assim, esse documento vem como um apoio às discussões e ao desenvolvimento de projetos educacionais das escolas, à reflexão da prática pedagógica, dos planejamentos das aulas, bem como da seleção de recursos didáticos e tecnológicos.

Assim, este trabalho apresenta uma forma de potencializar o ensino-aprendizagem da disciplina de Matemática mediado pelas tecnologias da informação e comunicação (TIC), disponíveis na Escola de Ensino Médio Nossa Senhora do Rosário, situada em Santa Cruz do Sul-RS. Primeiramente, foi apresentado um breve estudo teórico sobre a utilização das novas tecnologias aplicadas à educação e, prioritariamente, do computador com acesso à Internet, e softwares educativos. Posteriormente, foram pesquisados os professores das séries finais ${ }^{5} \mathrm{da}$

\footnotetext{
${ }^{5}$ A Escola Estadual de Ensino Médio Nossa Senhora do Rosário, contempla alunos do Ensino Fundamental e Ensino Médio.
} 
KIPPER, D.; FRUET, F. S. O. KINAST, E. J.

escola pesquisada, a fim de investigar quais TIC estão sendo utilizadas no ensinoaprendizagem de Matemática por esses professores, bem como analisar como está ocorrendo a integração desses recursos tecnológicos, nesse processo. Para a realização deste trabalho, também foi investigada a existência de uma formação inicial ou continuada desses docentes, com relação à utilização das TIC na educação.

Para isso, esta pesquisa concentrou-se em uma investigação de abordagem qualitativa, visto que apresentou e comparou qualitativamente as respostas dos docentes pesquisados.

\section{TECNOLOGIAS DE INFORMAÇÃO E COMUNICAÇÃO NO CONTEXTO ESCOLAR}

Através de visitas, percebe-se que nossas escolas estão cada vez mais equipadas com ferramentas tecnológicas, aparelho de som, DVD, TV, computadores com acesso à Internet. Porém, se a inclusão das mesmas não for adequada para o ensino-aprendizagem, não há motivos relevantes para a sua manutenção no ambiente escolar.

Para Almeida (2005), o advento das TIC, resultante da junção entre informática e telecomunicações, originou novos desafios e oportunidades para a incorporação de tecnologias na escola em relação às diferentes formas de representação e comunicação de ideias. Para a autora, as tecnologias, na sala de aula, propiciam a interação e a construção colaborativa de conhecimento, evidenciando o potencial de instigar o desenvolvimento das habilidades de escrever, ler, interpretar textos e hipertextos.

Nesta linha de pensamento, observa-se que não se trata da mesma leitura realizada do material impresso (livros, revistas, jornais, entre outros). Na perspectiva de Almeida (2005), a leitura de um texto digital, a qual é realizada na tela de um computador, está baseada em indexações, conexões entre ideias e conceitos articulados por meio de links (nós e ligações), que conectam informações representadas sob diferentes formas, tais como palavras, páginas, imagens, animações, gráficos, sons, clipes de vídeo, etc.

Para a autora, o uso de hipertexto rompe com as sequências estáticas e lineares de caminho único, com início, meio e fim fixados previamente. O hipertexto possibilita ao leitor seguir caminhos próprios de pesquisa, ou seja, ler de acordo com o seu interesse, ao saltar entre as informações e estabelecer suas próprias ligações e associações. Além disso, o leitor interage com o texto assumindo um papel ativo e tornando-se coautor do hipertexto. 


\section{UM ESTUDO DAS POTENCIALIDADES DO ENSINO-APRENDIZAGEM DE MATEMÁTICA MEDIADO PELAS TECNOLOGIAS DE INFORMAÇÃO E COMUNICAÇÃO}

Vive-se em um mundo tecnológico, onde cada vez mais, o papel está sendo substituído pelos textos digitais, uma forma mais prática e menos prejudicial ao meio ambiente. A tecnologia também vem a ser mais uma ferramenta na sala de aula, não modificando os conteúdos científicos já existentes, mas sim servindo como meio para potencializar o ensinoaprendizagem. Nesse sentido, encontram-se como auxílio a novas práticas pedagógicas, no ensino básico, jogos educativos digitais, textos disponíveis na Internet, diversos programas e sítios educativos. Deste modo, o professor precisa estar capacitado para, de forma competente, integrar estes recursos digitais à sala de aula.

Em contrapartida, Silva (2005), refere-se à escrita manuscrita, como um elemento de maior importância para uma educação mediada pelas tecnologias. Para ele, mídias impõem à escola uma reorganização espacial, arquitetônica e de serviços, de modo que possa circular condignamente a favor do ensino e da aprendizagem. O autor reflete que até o momento, em pleno início do terceiro milênio, em meio às sociedades da informação e do conhecimento, são raras as escolas que dispõem de espaços planejados para suas bibliotecas, que dirá serviços biblioteconômicos para a organização e a dinamização dos livros porventura acumulados, ao longo do tempo. O autor ainda adverte que as demais mídias, caso fossem levadas de forma efetiva para as escolas, causariam alterações radicais nos espaços físicos, necessitando da sofisticação dos mesmos, bem como de recursos humanos.

Enquanto isso, o livro precisa da biblioteca e do bibliotecário, o computador precisa da sala de informática e do técnico para mantê-la em ordem e atualizada; a televisão precisa da sala de projeção ambientada e do responsável pelos audiovisuais da escola, assim como as demais mídias e recursos tecnológicos. O referido autor alerta que essas sugestões não devem ser entendidas como luxos ou supérfluos dentro de um espaço escolar; mas sim, que esses elementos sejam tomados como imprescindíveis para uma educação que se volte objetivamente para a mídia em termos de produção, da construção do conhecimento dentro da escola.

Silva (2005), pondera que o computador passa ser uma ferramenta na alfabetização e construção do conhecimento. Mais do que isto, para o uso desta máquina o aluno necessita das habilidades básicas como ler e escrever, isto é, o computador impõe ao sujeito o domínio das competências do ler e escrever. Para o autor,

A escrita e a leitura virtuais são, na sua origem, antes de tudo, "escrita" [...]. O problema da escola e dos professores é como melhorar ambas - e as demais 
existentes - em favor das competências comunicacionais dos estudantes, ao longo de sua história de escolarização. Além disso, em termos de seqüências pedagógicas em direção ao aprofundamento de conteúdos ou temas, o professor deve possuir conhecimento e sensibilidade para decidir quais veículos e linguagens privilegiar de modo a levar os seus estudantes à melhor compreensão desses conteúdos. (SILVA, 2005, p. 33).

Cabe ao professor provocar a criticidade do aluno, em relação ao que lhe é exposto, tanto em meios virtuais como impressos,

[...] cabe-me insistir mais uma vez na necessidade de conhecimento da sintaxe e dos efeitos de cada meio de comunicação por parte dos professores, de modo que a seleção, o manejo e o uso não gerem desastres na formação dos estudantes. (SILVA, 2005, p. 34).

Ainda de acordo com referido autor, a comunicação escrita, especialmente aquela provocada por livros ou similares, permanece e permanecerá indispensável não apenas para a fruição da literatura, nem somente no sentindo de receber informações, mas também sobre refletir as mesmas, pois é preciso adentrar criticamente nas informações fornecidas pela sociedade. O autor ainda chama atenção para o entusiasmo que é dado para o uso das tecnologias. Para ele, este entusiasmo muitas vezes pode ofuscar o bom-senso ou o equilíbrio quando da utilização das mídias pelos professores e, ao mesmo tempo, pode elevar as novas tecnologias audiovisuais à condição de panacéia, servindo como "remédio para a cura de todos os males" da educação escolarizada brasileira.

Já na concepção de Soares (2001 citado por ALMEIDA, 2005), a leitura do hipertexto na tela inicia e termina no ponto que o leitor decide, o qual pode ter liberdade e autonomia para intervir no texto e reconstruí-lo. Deste modo, na percepção do autor, a comunicação pela tela está criando não só novos gêneros da escrita, mas também está inovando o próprio sistema da escrita.

Para Almeida (2005), outros recursos tecnológicos também permitem o registro de ideias e de visões de mundo por meio da escrita. Porém, até o momento, apenas a tecnologia de informação e comunicação assinalam o erro como algo que pode ser revisto e reformulado instantaneamente para produzir novos saberes.

Para a autora, é importante integrar as potencialidades das tecnologias nas atividades pedagógicas, de modo que favoreça a representação textual e hipertextual do pensamento do aluno. Esta possibilidade de selecionar e articular as informações estabelecem novas articulações com conhecimentos e desenvolvem a espiral da aprendizagem. Para isso, 
[...] o professor também é desafiado a assumir uma postura de aprendiz ativo, crítico e criativo, articulador do ensino com a pesquisa, constante investigador sobre o aluno, sobre seu nível de desenvolvimento cognitivo, social e afetivo, sobre sua forma de linguagem, expectativas e necessidades, sobre seu estilo de escrita, sobre seu contexto e sua cultura. (ALMEIDA, 2005, p. 40).

Neste caso, o professor passa a ser mediado com conhecimento, apresentando ao aluno possibilidades para a construção do conhecimento. O professor aprende em conjunto com ele, aumentando assim a aproximação na relação professor-aluno.

\section{A INTEGRAÇÃO DAS TECNOLOGIAS NO ENSINO-APRENDIZAGEM DE MATEMÁTICA}

Antes de falarmos da integração das Tecnologias no Ensino-aprendizagem em Matemática, temos que pensar sobre a Educação Matemática. Parafraseando Bicudo (1987), é preciso revisar o Ensino da Matemática, refletindo sobre sua vivência no passado, situando o seu ensino e iniciando um campo reflexivo acerca de uma Educação Matemática necessária e crítica, focalizando o ato educativo que abranja tanto o ato cognitivo quanto a relevância social do ensino dessa ciência como ato político.

Para Bicudo (1987), o ensino tradicional da Matemática não prezava por um repeito pela criatividade do aluno. A autora chama atenção à situação do ensino tradicional da Matemática, no qual a ação e prática tem ocupado um lugar de primazia e a filosofia é deixada de lado. A autora, em sua pesquisa, salienta que a Matemática ensinada tradicionalmente, sem nenhuma referencia à história de sua construção, utilizava-se de demonstrações e exposições, na ausência da comunicação entre quem ensina e quem aprende.

Já a respeito da natureza da matemática e do seu ensino, D’Ambrósio (1996), observa que a matemática ensinada hoje nas escolas é descontextualizada e fora da realidade na qual estão inseridos os alunos, ou seja, morta. O mesmo aponta que é preciso dar dinamismo ao currículo da Matemática, dentro dessa perspectiva salienta:

Em educação matemática assistimos na década de 1970 ao movimento da matemática moderna entrando em declínio em todo mundo. Mas não há como negar que desse desenvolvimento ficou um ou outro modo de conduzir aulas, com muita participação dos alunos, com uma percepção da importância de atividade, eliminando a ênfase antes exclusiva em contas e carroções. (D’AMBROSIO, 1996, p. 59). 
Na visão de Bicudo (1987) e D’Ambrósio(1996), a Matemática deve ser ensinada na sua relação com o mundo humano. É preciso experimentá-la, construí-la e não somente abstraí-la através de meras demonstrações. Portanto, é preciso inovar, repensar o ensino da Matemática mais atrativo e relevante para o educando. Nessa linha de pensamento, Baldin (2008), aponta para a introdução de ferramentas tecnológicas na prática escolar como aspectos inovadores nas diretrizes que norteiam a educação básica no Brasil, os Parâmetros Curriculares Nacionais (PCN). A introdução dessas tecnologias não acarreta apenas na mudança das atitudes dos alunos, mas principalmente na preparação dos professores que irão utilizar esses recursos.

No entanto, para que as tecnologias tenham uma função inovadora no ensino da Matemática, as mesmas devem aludir às inovações metodológicas na construção do conhecimento e em atividades investigativas. Para Baldin (2008), a tecnologia possibilita a execução de atividade de Laboratório, fazendo o uso de problemas contextualizados de Matemática, introduzindo técnicas de modelagem, análise crítica de resultados mediados pelas tecnologias, habilidades na resolução de problemas, criando um ambiente favorável para atividades integradas.

D’Ambrósio (1996), cita que as calculadoras ficam mais acessíveis, o ensino na matemática e mais tarde os computadores. Do mesmo modo, Fiorentini e Lorenzato (2007), revelam que o aparecimento das novas tecnologias, levou os educadores matemáticos a tentarem usar no ensino. Na década de 1990, surge então uma nova terminologia, as TIC: resultante da fusão entre as tecnologias da informação com a as tecnologias da comunicação. Segundo o autor, estas tecnologias além de permitir que o estudante aprenda de uma forma inovadora os conteúdos tradicionais, também permite explorar conteúdos novos, como os fractais, por exemplo. O autor chama atenção para que as TIC na educação, não sejam vista como uma solução para todos os males da educação atual, pois não basta equipar as escolas com as novas tecnologias, é preciso verificar se os professores sabem utilizá-las na prática escolar com eficácia.

Diante desse posicionamento, Borba e Penteado (2001), sugerem que a relação entre a informática e a educação matemática não pode ser pensada de forma dicotômica, mas sim como a transformação da própria pratica educativa. Segundo os autores, pesquisas feitas pelo GPIMEM - Grupo de Pesquisa em Informática outras Mídias e Educação Matemática -, apontam que trabalhar com os computadores abre perspectivas para a profissão docente. Os 


\section{UM ESTUDO DAS POTENCIALIDADES DO ENSINO-APRENDIZAGEM DE MATEMÁTICA MEDIADO PELAS TECNOLOGIAS DE INFORMAÇÃO E COMUNICAÇÃO}

referidos autores relatam que na década de 70, quando iniciaram as discussões sobre o uso da tecnologia informática na educação, imaginava-se que os professores seriam substituídos, pelas máquinas. Com o passar do tempo e após diversos estudos, contatou-se que a substituição do professor por máquinas não era algo com que se preocupar. Segundo os autores, o professor ganha um papel destaque nesses novos ambientes informáticos. O uso das TIC na educação, pressupõe mudança na prática docente, como também da sua postura em relação ao uso das mesmas.

Borba e Penteado (2001) acreditam que a discussão sobre a informática na educação matemática deva ser compreendida como educação para cidadania, envolvendo discussão sobre valores pessoais e da sociedade como um todo. Nesse sentido, o acesso à informática deve ser visto como um direito, tanto nas escolas públicas como nas particulares, possibilitando ao estudante usufruir da alfabetização tecnológica. Os autores destacam que a informática na escola deve estar ligada à cidadania.

Conforme Almeida (2005), a utilização destas tecnologias na escola, em especial dentro da sala de aula, impulsiona a abertura desses espaços ao mundo e ao contexto, permitindo assim, articular as situações globais e locais, sem, contudo abandonar o universo de conhecimentos acumulados ao longo do desenvolvimento da humanidade. Para a autora, tecnologias e conhecimentos se integram para produzir novos conhecimentos permitindo compreender as problemáticas atuais e desenvolver projetos, em busca de alternativas para a transformação do cotidiano e a construção da cidadania. Desse modo, a partir da busca e da organização de informações procedentes das diferentes fontes e tecnologias, valoriza-se a articulação entre novas formas de representação de conhecimentos por meio das mídias e respectivas formas de linguagem que mobilizam pensamentos criativos, sentimentos e representações, contribuindo para a comunicação, a interação entre pessoas e objetos de conhecimento, a aprendizagem e o desenvolvimento de produções.

Primeiramente, abordar-se-á sobre a calculadora. Conforme Tahan (1961), a máquina de calcular foi um dos mais importantes segredos da guerra, uma máquina maravilhosa que permite efetuar cálculos matemáticos que até aquele momento eram demasiadamente difíceis ou laboriosos. Com esta máquina, esses cálculos tornaram-se simples e rápidos, o que revolucionou a engenharia moderna, introduzindo uma nova era em projetos industriais, pois a produção deixou de ser lenta e custosa. 
De acordo com Soares, Loureiro e Veloso (1989), a calculadora é utilizada em diferentes atividades práticas e profissionais para a realização de cálculos. Na escola, é utilizada pelos alunos em disciplina de natureza técnica e em cursos técnicos científicos, constituindo-se na disciplina de Matemática do ensino superior, uma ferramenta com grandes potencialidades educativas.

A integração do computador, de acordo com Mendes (2009), exerce um papel decisivo no ensino da Matemática, em virtude das possibilidades de construção de modelos virtuais para a Matemática imaginária. Conforme afirma o autor, apresenta riscos e vantagens simultaneamente, de acordo com o uso e a proposta pedagógica em que está apoiado.

Para Mendes (2009), a informática em relação ao ensino da Matemática, é considerada uma das mais importantes das componentes das TIC para a efetivação da aprendizagem matemática no mundo moderno. Para o autor, a relação da informática com a Educação Matemática se estabelece a partir das perspectivas metodológicas atribuídas à informática como meio de superação dos obstáculos encontrados pelos professores e estudantes no processo ensino-aprendizagem.

Em consonância com estes autores, os PCN (BRASIL, 1997b), referem-se às TIC como um recurso que vem como um desafio para escola: o de incorporá-las à pratica docente, tradicionalmente apoiada na escrita e oralidade, como as novas formas de comunicar-se e conhecer.

\footnotetext{
O computador deve ser visto como um recurso didático que traz uma gama enorme de possibilidades ao processo ensino-aprendizagem de Matemática. Não se deve perder de vista que seu caráter lógico-matemático pode ser um bom aliado do desenvolvimento cognitivo dos alunos, por permitir distintos ritmos de aprendizagem, por constituir-se fonte de conhecimento e aprendizagem, uma ferramenta para o desenvolvimento de habilidades, por possibilitar que os educandos possam aprender a partir de seus erros, junto com outras crianças, trocando e comparando. (BIANCHI, 2003, p. 2).
}

O acesso a calculadoras e computadores - e outros tipos de tecnologias - é algo comum e frequente na vida cotidiana da população. A calculadora pode ser vista como uma ferramenta tecnológica motivadora na realização de tarefas, podendo ser empregada como um recurso para ser utilizado em atividades comerciais, entre outras áreas. Já o computador é apontado como um instrumento que traz várias possibilidades ao processo de ensinoaprendizagem da Matemática, pois já começa a integrar muitas experiências educacionais, podendo ser utilizado como uma ferramenta para o desenvolvimento de várias habilidades. 


\section{UM ESTUDO DAS POTENCIALIDADES DO ENSINO-APRENDIZAGEM DE MATEMÁTICA MEDIADO PELAS TECNOLOGIAS DE INFORMAÇÃO E COMUNICAÇÃO}

O uso de recursos tecnológicos no ensino da Matemática traz significativas contribuições no processo ensino-aprendizagem, de acordo com os PCN, na medida em que:

- Relativiza a importância do cálculo mecânico e da simples manipulação simbólica, uma vez que por meio de instrumentos esses cálculos podem ser realizados de modo mais rápido e eficiente;

- $\quad$ Evidencia para os alunos a importância do papel da linguagem gráfica e de novas formas de representação, permitindo novas estratégias de abordagem de variados problemas;

- $\quad$ Possibilita o desenvolvimento, nos alunos, de um crescente interesse pela realização de projetos e atividades de investigação e exploração como parte fundamental de sua aprendizagem;

- $\quad$ Permite que os alunos construam uma visão mais completa da verdadeira natureza da atividade matemática e desenvolvam atitudes positivas diante de seu estudo. (BRASIL, 1997b, p. 43).

O referido documento também apresenta como o computador pode ser usado nas aulas de matemática:

- Como fonte de informação, sendo um recurso para alimentar o processo ensino-aprendizagem;

- $\quad$ Como auxiliar no processo de construção de conhecimento;

- Como meio para desenvolver autonomia pelo uso de softwares que possibilitem pensar, refletir e criar soluções;

- Como ferramenta para realizar determinadas atividades - uso de planilhas eletrônicas, processadores de texto, banco de dados etc. (BRASIL, 1997b, p. 44).

De acordo com esse documento, percebe-se que essas habilidades são construídas na matemática, a partir do uso das tecnologias e de instrumentos de mediação.

Segundo os PCN (BRASIL, 1997b), o da calculadora é um recurso útil para a verificação de resultados, correção de erros, podendo ser um valioso instrumento de autoavaliação. O que vai ao encontro de Lopes (1999, p.77). Para ele, “a calculadora é um objeto matemático por excelência" e além de ter uso e função utilitária limitada, também tem outras finalidades voltadas para aspectos recreativos de fortes componentes afetivos e estéticos associados à investigação matemática. Para o autor, não permitir que o aluno utilize a calculadora é o mesmo que lhe dizer que a escola está fora da sociedade, ou seja, fora da realidade.

[...] no mundo atual, saber fazer cálculos com lápis e papel é uma competência de importância reativa que deve conviver com outras modalidades de cálculo, como o cálculo mental, as estimativas e o cálculo produzido pelas calculadoras, portanto, não se pode privar as pessoas de um conhecimento que é útil em suas vidas. (BRASIL, 1997b, p.45). 
O que o referido documento evidencia é o uso da calculadora como instrumento para promover a aprendizagem, pois possibilita ao aluno à investigação matemática, pois ela serve como ferramenta facilitadora das explorações numéricas. Ela também é útil na verificação dos resultados, na correção dos erros, por parte do aluno. Na interpretação de Soares, Loureiro e Veloso (1989), a utilização da calculadora em relação ao ensino-aprendizagem traz vantagens, pois permite libertar o ensino e a aprendizagem da Matemática do excessivo peso do cálculo; permite o desenvolvimento de capacidades de estimação e cálculo mental, que a todo o momento são requeridas por outros objetivos matemáticos; o controle de diferentes técnicas de cálculo; enriquece a construção de conceitos; direciona o ensino e a aprendizagem da matemática para o desenvolvimento do espírito crítico e da atitude investigativa; estimula diversas formas de raciocínio; encara novas dimensões na resolução de problemas; diversifica estratégias adequadas na resolução de problemas; estimula a atividade Matemática e, ao aluno, a construção do próprio conhecimento de forma ativa e criativa.

Apesar de a calculadora ser, atualmente, uma máquina tão simples e de fácil acesso, presente nos diversos setores econômicos da sociedade, percebe-se o quanto é restrito o seu uso em sala de aula. Do mesmo modo, os computadores ainda possuem muitas restrições para que os professores possam empregá-los nas aulas; ainda que os avanços tecnológicos estejam cada vez mais presentes na vida cotidiana.

Conforme destaca Eves (2004, p. 684-686):

[...] os progressos redundaram nos espantosos sofisticados computadores eletrônicos atuais, descendentes dos antigos instrumentos de cálculo mecânico simples, contam entre as façanhas matemáticas mais importantes do século XX. Particularmente revolucionaria foi a idéia de uma maquina que além de operar com dados armazenasse um programa de instruções.

Atualmente, assim como as calculadoras, estas máquinas estão inseridas em empresas, na administração pública, em setores de engenharia e muitas outras atividades. Assim, tornaram-se instrumentos essenciais ao desenvolvimento de empresas e até mesmo de uma nação, transformando-se numa área de importância cada vez maior. Por isso, explica-se a necessidade de pessoas capacitadas nesta área, o que implica na formação de estudantes em todos os níveis escolares, a fim de terem fluência tecnológica. De acordo com os PCN (BRASIL, 1997b), o mercado de trabalho necessita de pessoas com novas qualificações profissionais, sendo uma delas o domínio das Tecnologias de Comunicação e Informação. De 
acordo com esse documento, o computador é um grande aliado do desenvolvimento cognitivo dos alunos, pois possibilita ao aluno aprender com os seus erros. O referido documento também relata que o uso do computador estabelece uma nova relação professor-aluno, aproximando-os e definindo uma nova visão do professor, não sendo mais um profissional pronto, mas sim um profissional em formação permanente.

Do mesmo modo, Valente (1996 citado por LORENZATO, 2006), defende que o uso inteligente do computador na educação é aquele que provoca mudanças na abordagem pedagógica vigente. De acordo com o autor, transformar o computador em uma ferramenta catalisadora e auxiliadora na transformação da escola é mais promissor do que apenas informatizar o processo de ensino.

Com relação às TIC, ainda se tem como ferramentas recursos audiovisuais, além do computador. Segundo Almeida (2005), mesmo que os recursos não estejam fisicamente instalados nos espaços escolares, a mídia audiovisual invade a sala de aula. A linguagem produzida na integração entre imagens, movimentos e sons atrai e toma conta das gerações mais jovens, cuja comunicação resulta do encontro entre palavras, gestos e movimentos, distanciando-se do gênero do livro didático e da tradicional sala de aula. Conforme a autora, a televisão e o vídeo são ótimos recursos para mobilizar os alunos em torno de problemáticas quando se intenta despertar-lhes o interesse para iniciar estudos sobre determinados temas ou trazer novas perspectivas para investigações em andamento.

Mas será que esses professores estão preparados para tal mudança, se muitos em sua formação pedagógica não tiveram contato com tecnologias, e outros mesmo tendo ainda, possuem aversão a qualquer tipo de tecnologia?

Nesse impasse, Araújo (2005, p. 23-24) adverte:

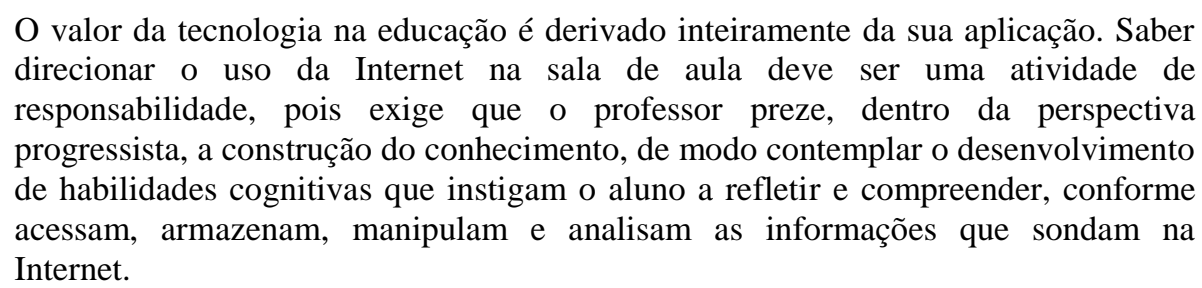

Não basta colocar nas escolas sofisticados laboratórios de informática, mas sim é preciso formar o professor para aprender a ensinar utilizando estes meios da melhor forma 
possível. É preciso quebrar a barreira entre o computador e a sala de aula, tornando-o algo simples, o cotidiano na vida escolar do aluno e do professor.

\section{1 o computador no ensino}

De acordo com Cattai (2007), faz-se necessário lembrar que o computador é o meio e não o fim. Eles servem como solucionadores de problemas, porém só se tornam úteis para o ensino-aprendizagem com a ajuda de um bom professor. Para que o uso da informática no processo de ensino torne-se o mais produtivo possível, é fundamental a elaboração de métodos e procedimentos didáticos.

Do mesmo modo, para Valente (1993 citado por CATTAI, 2007), a quantidade de programas educacionais e as diferentes modalidades do uso do computador demonstram a utilidade da tecnologia para o ensino-aprendizagem. Para o autor, na implantação do computador na educação são necessários quatro elementos: o computador, o software educativo, o professor capacitado para o uso do computador como meio educacional e o aluno. Enfatiza-se que o computador só pode ser utilizado na educação com um software adequado.

Como afirma Cattai (2007), os diversos tipos de softwares usados na educação podem ser classificados de acordo com os seus objetivos pedagógicos. Dentre os diversos tipos de software, o autor cita Simulação e Modelagem, Programação, Multimídia, Internet, entre outros.

a) Jogos. A utilização de jogos educativos contribui para a melhoria do processo ensino-aprendizagem e proporciona ao aluno uma maneira lúdica de aprender. $\mathrm{O}$ autor cita como dois exemplos de jogos educativos: (i) Mr. Math 2000 - este jogo tem por finalidade diagnosticar algumas dificuldades do ensino da Matemática, permitindo ao usuário testar seus conhecimentos matemáticos); (ii) Tangran - antigo quebra-cabeça chinês utilizado para aulas de geometria, disponibilizado online no endereço $<$ http://www.chinaonline.com.br/artes_gerais/tangran/jogue_tangran.asp $>$;

b) Exercícios e Práticas. Resume-se a realizar exercícios em um livro eletrônico, cujo resultado pode ser avaliado pelo próprio computador. Estes tipos de prática estão disponíveis em softwares fáceis de serem desenvolvidos. Cattai (2007), cita como exemplo o ParaWord e o Polly 2000, ambos disponíveis no GEIAAM - UFSC (Grupo de Estudos de Informática 
Aplicada à Aprendizagem Matemática da Universidade Federal de Santa Catarina). O ParaWord tem como objetivo a construção de parábolas e de equações simples. O Polly 2000 tem por objetivo auxiliar o aluno na classificação de triângulos e quadriláteros.

c) Tutoriais. São informações que estão disponíveis de forma prévia e organizada para o aluno, de modo a deixar o computador uma máquina de ensinar. Cattai (2007) cita como exemplo de tutoriais, o IEDer e o ApliDer, ambos do GEIAAM - UFSC. O IEDer, tem por objetivo ensinar o aluno na aprendizagem da Derivada. Já o ApliDer, tem por objetivo auxiliar os alunos na Resolução de Problemas de Aplicações das Derivadas. Softwares dessa natureza constituem o ponto forte do computador na escola, pois permitem simular situações fictícias. Para o autor, quando se utiliza simuladores no processo de ensino-aprendizagem, destaca-se a vantagem deles oferecerem a possibilidade de o aluno desenvolver hipóteses, testá-las, analisar resultados e redefinir conceitos.

d) Micromundos. São os principais softwares representantes da categoria de Ambientes Interativos de Aprendizagem (AIA). Este tipo de programa requer a exploração livre do aluno, pois é ele que conduz o micromundo através de experimentos. Na aprendizagem de Matemática, a ideia básica do uso do micromundo é a de encorajar o estudante a explorar o ambiente na resolução de problemas, podendo assim melhorar o desenvolvimento das estratégias. São exemplos de micromundos: (i) Geometria Dinâmica (Gb) - permite construções geométricas a partir de objetos base; (ii) Cabri-Geométri II explora as propriedades dos objetos e suas relações, construção de figuras geométricas, histórico de construções e formulação de hipóteses e conjecturas; (iii) Régua e Compasso $(C a R)$ - é software de geometria plana.

e) Sistemas de tutorias. Através de um software de Tutoria, o usuário (professor ou aluno) pode criar e apresentar aulas, apostilas eletrônicas e outros tipos de programas educacionais. Assim, alunos e professores podem criar seus próprios conteúdos e a relação ensino-aprendizagem fica mais dinâmica, pois eles trabalham juntos durante o processo de criação do projeto multimídia e o professor assume o papel de orientador. $\mathrm{O}$ autor cita como exemplo de sistema de tutoria, o PowerPoint da Microsoft, podendo ser utilizado basicamente para aulas expositivas. Mas também é importante lembrar que existe outro software similar, como o BrOffice Impress do Linux Educacional.

f) Sistemas de Computação Algébrica ou Sistemas de Álgebra Computacional (Em inglês, Computer Algebra System - CAS). São programas que facilitam o cálculo com 
KIPPER, D.; FRUET, F. S. O. KINAST, E. J.

matemática simbólica, pois permitem cálculos algébricos com equações, fórmulas, expressões, etc. Para a sua utilização no ensino é preciso a implementação de propostas pedagógicas. Tem-se como exemplos destes tipos de softwares: (i) Maple - sistema de computação algébrica desenvolvido por Waterloo Maple Inc; (ii) Mathematica - é tido como um dos mais eficientes programas de cálculo algébrico e é utilizado por um grande número de engenheiros, analistas, cientistas, educadores e estudantes; (iii) MuPAD - é um ambiente desenvolvido para cálculos matemáticos, sejam eles simbólicos, numéricos ou gráficos; (iv) Yacas - extremamente promissor, em desenvolvimento por Ayal Pinkus, semelhante ao Mathematica.

g) Planilhas Eletrônicas. São utilizadas geralmente por empresas para planejamento e controle financeiro. O software Microsoft Excel é um exemplo de uma planilha eletrônica, pois é um processador eletrônico que analisa dados em planilhas, gráficos e mapas. Também possui outras funções internas, como funções matemáticas, trigonométricas, financeiras, estatísticas e lógicas. Também existem outros tipos de planilha eletrônica, como o OpenOffice.org Calc, similar ao Microsoft Excel, mas que possui uma série de funções que não estão presentes no Excel.

\section{CONTEXTO DA PESQUISA, DESCRIÇÃO E ANÁLISE DOS RESULTADOS}

Neste tópico serão apresentados os dados obtidos nas visitações e entrevistas com as professoras e a supervisora da instituição pesquisada, como também a metodologia utilizada para a pesquisa. Durante as entrevistas e observações, visou-se observar os aspectos físicos e pedagógicos da escola, a fim de perceber o objeto de estudo a ser investigado, como também, o perfil profissional das professoras pesquisadas.

\subsection{Metodologia e procedimentos de pesquisa}

A presente pesquisa utiliza-se de uma abordagem de pesquisa qualitativa, pois segundo Lüdke e André (1986), este tipo de pesquisa supõe o contato direto e prolongado do pesquisador com o ambiente e a situação que está sendo investigada, ou seja, o pesquisador vai a campo, presencia situações. De acordo com Bogdam e Biklen (1982 citado por LÜDKE; 
ANDRÉ, 1986), a pesquisa qualitativa envolve a obtenção de dados descritivos, obtidos no contato direto dos pesquisados com a situação estudada, por isso a escolha deste método.

A construção do estudo proposto para a referida pesquisa valeu-se de cinco momentos distintos para investigar como (e se) os professores de Matemática das séries finais estão integrando as TIC em seu fazer pedagógico, além de averiguar se há uma formação continuada destes profissionais. Primeiramente, foi realizado um levantamento bibliográfico referente à integração das TIC no ensino-aprendizagem, no intuito de compreender a sua aplicação dentro da educação.

A segunda parte da pesquisa se deu através de visitas ao estabelecimento e contato com os profissionais pesquisados, para conhecer o funcionamento da escola. Para isso, foi realizada uma entrevista com a supervisora da escola, a fim de investigar que ações a escola realiza em prol da integração das TIC no ensino-aprendizagem. Segundo Cartwrigtht (1987 citado por FESTINGER; KATZ, 1987), muitas das técnicas de investigação, desenvolvidas por psicólogos sociais, tiveram como objetivo a produção de material simbólico, verbal ou de outro tipo. A entrevista é um exemplo importante nesta técnica; ao propor perguntas, o investigador estimula a conduta verbal que, segundo se espera, proporcionará indicadores em algumas características do indivíduo ou de sua relação com os demais.

O terceiro momento ocorreu com a realização de uma entrevista semi-estruturada ${ }^{6}$ aos professores de Matemática das séries finais do Ensino Fundamental, com o objetivo de verificar os métodos adotados para integrar as TIC, observando se (e como) os professores utilizam em sua prática pedagógica, as mídias da educação (eventualmente) oferecidas pela escola. As conversas com as profissionais pesquisadas aparecem transcritas neste trabalho.

No quarto momento, realizou-se a análise das práticas escolares adotadas pelos professores pesquisados para incluírem as tecnologias em sala de aula. Nesse momento, verificou-se quais tecnologias de comunicação e informação são utilizadas pelas profissionais, e como são utilizadas. O quinto e último momento se deu através da elaboração deste artigo, finalizado com as conclusões a partir da aplicação desta pesquisa.

\subsection{Ambiente pesquisado}

\footnotetext{
${ }^{6}$ Entende-se por entrevista semi-estruturada aquela que se desenvolve tendo como referência um esquema básico, porém aplicado com flexibilidade, permitindo que o entrevistador/pesquisador faça as necessárias adaptações (LÜDKE; ANDRÉ, 1986).
} 
Como objeto desta pesquisa, foi selecionada a Escola Estadual de Ensino Médio Nossa Senhora do Rosário, localizada no município de Santa Cruz do Sul-RS. A caracterização da escola pesquisada teve como base a observação do espaço físico, bem como a realização de entrevista semiaberta, com a supervisora, a qual disponibilizou o Projeto Político Pedagógico $(\mathrm{PPP})^{7}$, e apresentou a estrutura do estabelecimento em relação ao aspecto tecnológico.

A escola possui 570 alunos e 52 professores, distribuídos em três turnos, a parte da manhã abrange o ensino fundamental e ensino médio, o turno da tarde abrange somente o ensino fundamental e o turno da noite abrange somente o ensino médio. A escola em estudo, está localizada próximo à Universidade de Santa Cruz do Sul (UNISC). Para contemplar o objeto de pesquisa foram entrevistados os dois professores que atendem as séries finais do ensino fundamental. De acordo com as observações realizadas, apresenta adequada infraestrutura. A escola em estudo também abrange alunos surdos, sendo que o ensino fundamental de alunos surdos é separado dos ouvintes, enquanto o ensino médio é em conjunto com os ouvintes, a escola é reconhecida como escola de Surdos. A avaliação dos alunos é por conceitos: A, B, C e D. O PPP, é voltado para os valores e para a formação da cidadania e da consciência crítica.

Com relação às TIC, a escola possui um adequado acervo de livros, contendo aproximadamente 12000 livros, também possui livros didáticos fornecidos pelo Governo do Estado, assinaturas de jornais, revistas, entre outros. Com relação aos aparelhos sonoros e audiovisuais, a escola possui:

- 2 TVs - dispostas em sala própria;

- 2 aparelhos de DVD, dispostos em sala própria junto com as TVs;

- 2 aparelhos de projetor de multimídia, um fixo em sala própria e outro móvel.

- 4 aparelhos de CD, móveis;

- uma rádio da própria escola, utilizada para ouvir música pelos alunos;

- Laboratório de Informática, para uso de toda escola conectado à Internet;

Esses recursos estão disponíveis para todos os professores, porém é necessária a reserva prévia dos mesmos, pois não há disponibilidade destes aparelhos, para todos os professores, simultaneamente. A escola não disponibiliza de profissional de apoio para o uso

\footnotetext{
7 Apresenta as finalidades, concepções e diretrizes do funcionamento da escola. Instrumento de autonomia da escola.
} 
dos recursos, cabe ao professor o manuseio dos mesmos. A escola também disponibiliza curso de formação continuada na educação para os docentes.

Quando foi questionado quanto ao incentivo pela escola referente ao uso das tecnologias, pelos professores, através de ações, projetos ou projeto político pedagógico. A supervisora relatou que:

A escola tem incentivado o uso das tecnologias, pelos professores de forma cotidiana através do uso do e-mail da escola para repassar informações, orientações, lembretes. Na formação pedagógica deste ano, foi tratado o tema Edu comunicação, buscando informar e motivar os professores para busca pessoal destes recursos; A Escola está construindo um site também com esse objetivo; que os professores enviem informações, relatos, trabalhos. Eatravés do site também façam suas buscas/pesquisas.

Com relação ao incentivo e disponibilidade de recursos na escola, percebeu-se que a escola possui adequada infraestrutura disponibilizando vários recursos para os professores.

Quanto à formação inicial ou continuada desses docentes, com relação às mídias na educação, a professora entrevistada fez o seguinte comentário:

Em 2009, a Escola em parceria com a UNISC, ofereceu Curso gratuito Básico de informática, no Laboratório de Informática. A $6^{\circ}$ CRE disponibiliza regularmente cursos gratuitos de informática. Infelizmente, nestes dois espaços, houve pouquíssima participação de nossos professores. Percebo que já há, um avanço, nesta área, aos poucos, no dia-a-dia, os professores estão se apropriando das ferramentas básicas (envio e recebimento de e-mail, digitação, pesquisas na internet, etc.) e também estão aceitando e incentivando os alunos a usarem estas ferramentas em seus trabalhos de pesquisas e de aulas, e não só para diversão e entretenimento. (Informação verbal).

Assim, de acordo com resposta da supervisora, percebe-se que há incentivo por parte das políticas públicas com relação à atualização do corpo docente dessa escola. Isso demonstra que, existe incentivo por parte das políticas públicas, porém ainda não há uma participação significativa por parte dos professores da escola pesquisada.

\subsection{Perfil e formação profissional dos professores pesquisados}

Para a realização deste trabalho, foram entrevistadas as duas professoras da disciplina de Matemática, as quais atuam nas séries finais do Ensino Fundamental - $5^{\mathrm{a}}$ a $8^{\mathrm{a}}$ séries - da 
Escola Estadual de Ensino Médio Nossa Senhora do Rosário. Com o propósito de investigar se e como estas profissionais utilizam as TIC no ensino-aprendizagem de Matemática, bem como pesquisar, analisar e investigar como está ocorrendo a integração desses recursos tecnológicos nesse processo e se há uma formação inicial ou continuada deste professores para a integração das TIC em sala de aula.

Para pesquisar sobre o perfil profissional dos docentes entrevistados, foram realizadas quatro perguntas referentes: a formação profissional; ao tempo de atuação no magistério; a série/ano em que trabalha; ao regime semanal de trabalho e carga horária.

As duas professoras pesquisadas apresentam as características dispostas no quadro 1.

Quadro 1 - Características dos professores pesquisados

\begin{tabular}{|c|c|c|c|c|c|}
\hline Prof. & Sexo & Área de formação & Série/ano que trabalha & $\begin{array}{l}\text { Anos de } \\
\text { docência }\end{array}$ & $\begin{array}{l}\text { Carga horária - } \\
\text { Hora/aula }\end{array}$ \\
\hline $\mathrm{P} 1$ & $\mathrm{~F}$ & $\begin{array}{c}\text { Matemática Licenciatura } \\
\text { Plena }\end{array}$ & $7^{\mathrm{a}}$ e $8^{\mathrm{a}}$ do Ensino Fundamental & 20 anos & $\begin{array}{l}20 \text { horas-aula e } 20 \\
\text { horas de vice-direção }\end{array}$ \\
\hline $\mathrm{P} 2$ & $\mathrm{~F}$ & $\begin{array}{c}\text { Matemática Licenciatura } \\
\text { Plena e Pedagogia }\end{array}$ & $\begin{array}{c}5^{\circ} \text { ano; } 5^{\mathrm{a}} \text { série, } 6^{\mathrm{a}} \text { série; } 2^{\mathrm{o}} \text { e } \\
3^{\mathrm{o}} \text { ano do Ensino Médio }\end{array}$ & 5 anos & 60 horas \\
\hline
\end{tabular}

Fonte: Autor

A partir dos dados do quadro 1, constatou-se que as duas profissionais entrevistadas possuem formação na área de Matemática ${ }^{8}$, ambas profissionais possuem de 40 h/a e 60 h/a.

Com relação à busca pela atualização nos assuntos tecnológicos, por meio de leituras ou realização de curso, percebe-se com a pesquisa, que P1 possui formação em Matemática, porém não realiza cursos de atualização voltados para o uso das tecnologias como recursos didático-pedagógicos, já P2 alega atualizar-se no que diz respeito às Tecnologias. A docente P2 afirma realizar frequentemente leituras sobre TIC aplicadas à Educação, também assiste informações na TV e pesquisa na Internet, ocasionalmente realiza curso de aperfeiçoamento e frequentemente participa de encontros, congressos e formação pedagógica voltados para educação em âmbito geral. ${ }^{9}$

\footnotetext{
8 A Secretaria de Educação permite que os professores atuem fora da sua área de formação, já que existe carência de profissionais em algumas áreas.

9 Informações apresentadas pelas próprias profissionais durante a entrevista.
} 
UM ESTUDO DAS POTENCIALIDADES DO ENSINO-APRENDIZAGEM DE MATEMÁTICA MEDIADO PELAS TECNOLOGIAS DE INFORMAÇÃO E COMUNICAÇÃO

\subsubsection{Opinião dos professores em relação ao uso das TIC aplicadas à educação}

Para analisar o trabalho docente relacionado à integração das tecnologias na sala de aula, realizaram-se as seguintes indagações:

a) Em sua opinião é possível ensinar utilizando as tecnologias nas aulas? Com relação à opinião das professoras em relação à possibilidade de ensinar utilizando as tecnologias nas aulas, P1 afirma que é possível através de pesquisas de conteúdos e jogos. Nesse mesmo sentido, P2 também afirma que é possível integrar as tecnologias por meio de jogos informatizados e pesquisas nas séries finais do Ensino Fundamental. Essa professora declara usar os jogos como Labirinto, Enigma das Frações presentes no site <http://escola.britannica.com.br/> e também utiliza como recursos, a Internet para pesquisas, vídeos de matemática para mostrar imagens mais reais do conteúdo desenvolvido e de fácil compreensão pelos alunos.

b) Você utiliza alguma mídia em sua prática pedagógica, como auxílio na metodologia ou como fonte de pesquisa para o planejamento? Ao pesquisar quais tecnologias e como as mesmas são utilizadas pelos professores pesquisados, verifica-se que, uma das docentes pesquisadas busca atualização relacionada às tecnologias digitais, sendo que a mesma relata fazer uso de diversas TIC em seu fazer pedagógico.

Quando se refere às tecnologias na prática pedagógica, como auxílio na metodologia ou como fonte de pesquisa para o planejamento dos professores pesquisados, apenas P2 declara integrá-las. Desse modo, foi perguntado a ela quais os recursos mais utilizados. P2 respondeu que organiza as atividades escolares mediadas por jornais, revistas, livros, computador conectado à Internet e calculadora. Quanto à forma de uso, P2 afirma utilizar ocasionalmente a TV, Vídeo ou DVD, para demonstração de vídeos com aulas explicativas. Já o computador (programas educacionais ou internet), utiliza frequentemente jogos e pesquisas. A calculadora é utilizada para agilizar os cálculos, porém não a utiliza no Ensino Fundamental, apenas no Ensino Médio, e livros/revistas/jornais também são utilizados com frequência para pesquisas e desenvolvimento do conteúdo.

A docente pesquisada, P1, em outro momento da entrevista, afirmou fazer uso frequente apenas da calculadora, a fim de facilitar os cálculos. Sendo este o único recurso tecnológico utilizado em suas aulas, citado pela professora pesquisada. 
KIPPER, D.; FRUET, F. S. O. KINAST, E. J.

c) Você busca atualizar-se nos assuntos relacionados às tecnologias digitais, através de leituras ou realização de cursos? Com relação a este questionamento, P1 e P2, em suas respectivas respostas, afirmaram não terem participado. Porém, P2, busca se atualizar através de leituras, pesquisas e do próprio contato direto com estes recursos.

d) Você se sente seguro para utilizar os recursos tecnológicos em suas aulas? Por quê? Quando questionadas a respeito da segurança das mesmas referente aos recursos tecnológicos, P2 assegura sentir-se segura: "Sim, pois as mesmas são de grande ajuda e importância e por serem aulas preparadas". O que a professora destacou, consiste na importância de um planejamento pautado em recursos tecnológicos, abordando conteúdos científicos de forma aplicada. Ao indagar P1, em outro momento, a docente revelou que: "Não. Não domino muito a área da informática."

A partir destas respostas, percebe-se que apenas uma das profissionais, domina o uso das tecnologias, conseguindo realizar um trabalho na sala de aula, utilizando recursos tecnológicos como ferramenta na prática de ensino, a fim de conduzir o aluno para uma construção de um conhecimento matemático integrado as tecnologias.

e) Você percebe alguma diferença na aprendizagem dos alunos, quando as aulas são mediadas por alguma tecnologia? Qual é a reação deles nessas aulas? Com relação à percepção na diferença da aprendizagem dos alunos, quando as aulas são mediadas por alguma tecnologia, P2 afirma perceber a diferença: "Sim, os alunos demonstram mais interesse pelas aulas e têm mais facilidade nas aprendizagens e conseguem assimilar com acontecimentos da sua realidade". No mesmo sentido, P1 faz o seguinte relato a respeito: "Acredito que as aulas ficam mais interessantes".

Apesar da professora P1, acreditar que os recursos tecnológicos são de grande valia para o ensino-aprendizagem, percebe-se que a mesma não os utiliza e tampouco se atualiza no que se refere ao uso das TIC. Com a pesquisa, percebe-se também que há disponibilidade destes recursos, como também incentivo por parte da escola para o uso das mesmas, como se verifica através do relato da supervisora entrevistada. Entretanto, ainda há resistência por parte de alguns professores para o uso das TIC. 


\section{CONSIDERAÇÕES FINAIS}

Estudar a realidade educacional de uma determinada instituição significa tecer relações entre as situações locais concretas com as situações externas e teorias estudadas de diversos autores, podendo assim criar possibilidades para a escola pesquisada, buscar estratégias para potencializar o ensino-aprendizagem da Matemática por meio do uso das TIC.

Os avanços da ciência e da tecnologia trazem consequências na transformação social e, por conseguinte fazem muitas e novas exigências à escola e aos professores. O acesso aos meios tecnológicos, bem como a sua disseminação na sociedade, é uma necessidade de desenvolvimento mundial como também do desenvolvimento do próprio indivíduo. Diante disso, espera-se do professor uma nova postura com relação ao ensino da Matemática, pois a matemática potencializada pelas TIC exige que o professor mantenha-se cada vez mais informado e participante desse mundo das TIC. Assim o professor vem assumindo um novo papel dentro do ensino da Matemática, uma vez que é preciso se apropriar de novas estratégias didático-pedagógicas para aplicá-las na própria prática docente.

O trabalho teórico-prático se desenvolveu de forma gratificante, porque além do levantamento bibliográfico, oportunizou a investigação das metodologias utilizadas por professores de Matemática, permitindo a análise e reflexão sobre o trabalho desenvolvido nesse ambiente. Assim, com esta pesquisa, a verificação de algumas estratégias empregadas pelos docentes para ensinar os conteúdos escolares da disciplina de Matemática, utilizando como ferramenta didático-pedagógicas, as TIC.

Com este trabalho, percebeu-se que existem incentivos por parte das políticas públicas para o aperfeiçoamento e atualização dos profissionais da educação, referentes à integração das tecnologias na sala de aula, embora muitos profissionais ainda não estejam usufruindo desses cursos.

Nesse sentido, observou-se que não basta apenas o oferecimento de cursos de aperfeiçoamento aos professores, mas sim um planejamento pedagógico por parte do gestor voltado para o uso das TIC, na prática docente. Desse modo, o gestor deve incentivar os professores a utilizar as habilidades e recursos tecnológicos, visando à melhoria do ensino e da prática docente; a fim de contribuir para um sistema de ensino de maior qualidade, para a formação de cidadãos mais informados e cientes da importância real do conhecimento matemático para o contexto social e econômico em que estão inseridos. 
KIPPER, D.; FRUET, F. S. O. KINAST, E. J.

Para que isso ocorra, a divulgação desta pesquisa será de grande valia para um diagnóstico do ensino da Matemática da Escola Estadual de Ensino Médio Nossa Senhora do Rosário. A partir deste estudo, abre-se a oportunidade para discutir sobre os diferentes recursos das TIC que os docentes podem usar para aumentar seu conhecimento pedagógico e a forma de ensinar a Matemática, incentivando os docentes a criarem um plano de uso das diversas ferramentas tecnológicas para incorporar em suas aulas.

Além disso, a escola deve criar possibilidades para a integração das tecnologias no fazer pedagógico dos professores em suas aulas. Para assim, promover a formação docente para o desenvolvimento de novos materiais de aprendizagem, como também rever o uso dos recursos disponíveis no ambiente escolar. Isso poderá envolver os participantes em uma discussão, a fim de estudarem metodologias possíveis, aplicáveis às séries finais do ensino fundamental, no ensino da Matemática, abordando o uso das tecnologias. Já as políticas públicas, além da promoção de cursos formação continuada em conjunto com a escola, precisaria se implementar políticas para incorporar habilidades tecnológicas no currículo escolar.

\title{
A STUDY OF THE POTENTIALITIES OF MATHEMATICS TEACHING AND LEARNING MEDIATED BY THE INFORMATION AND COMMUNICATION TECHNOLOGIES
}

\begin{abstract}
In this paper, the mathematics teachers of the State Escola Estadual de Ensino Médio Nossa Senhora do Rosário, located in Santa Cruz do Sul-RS, were investigated whether and how they are using the information and communication technologies (ICT) in teaching your doing in grades of elementary school and whether there are initial or continuing training of teachers in ICT in education. First we held a bibliographic survey concerning to the use of ICT in teaching, especially in mathematics. The second part of this study was through the visit to this institution, as well as through a semi-open interview with the surveyed teachers in order to investigate the methods used by mathematics teachers for the integration of ICT in mathematics classes and their update to use the same. When performing the search we realized that only one of the surveyed teachers uses ICT to enhance the teaching of mathematics. He also seeks to upgrade himself in the method. Based on these data we saw
\end{abstract}


UM ESTUDO DAS POTENCIALIDADES DO ENSINO-APRENDIZAGEM DE MATEMÁTICA MEDIADO PELAS TECNOLOGIAS DE INFORMAÇÃO E COMUNICAÇÃO

the need for the updating of teachers of the elementary school final grades for the use of ICT in the teaching of mathematics, because the school has sufficient resources for education mediated by these technologies. Accordingly, it is necessary to create, in conjunction with the management, an educational planning focused on the use of ICT in the teaching practice.

Keywords: Information and Communication Technologies; Teaching and Learning; Mathematics

\section{UN ESTUDIO DE LAS POTENCIALIDADES DE LA ENSEÑANZA Y APRENDIZAJE DE MATEMÁTICA MEDIADA POR LAS TECNOLOGÍAS DE LA INFORMACIÓN Y COMUNICACIÓN}

\section{Resumen}

En este trabajo, los profesores de Matemática de la "Escola Estadual de Ensino Médio Nossa Senhora do Rosário", situada en "Santa Cruz do Sul-RS", fueron investigados sobre si y cómo están utilizando las tecnologías de la información y de la comunicación (TIC) en su quehacer pedagógico en los grados finales de la enseñanza fundamental y también si hay una formación inicial o continuada de esos docentes en relación a las TIC en la educación. Primero, fue realizado un levantamiento bibliográfico referente a la integración de las TIC en la enseñanza y aprendizaje, especialmente, de la Matemática. La segunda parte de este estudio se realizó a través de la visita a esa institución, como también por medio de entrevistas semiabiertas con los profesores investigados, con el objetivo de constatar los métodos adoptados por los profesores de Matemática para la integración de las TIC en las clases de Matemática y su actualización para el uso de las mismas. Al realizar la investigación, se notó que apenas uno de los docentes investigados utiliza las TIC, para potencializar la enseñanza de la Matemática, como también busca la actualización para el uso de las mismas. A partir de esos datos, se constató la necesidad de la actualización de los profesores de los grados finales de la enseñanza fundamental para la utilización de las TIC en la enseñanza de la Matemática, pues la escuela posee recursos adecuados para una enseñanza mediada por las tecnologías. En ese sentido, es necesario buscar, en conjunto con la gestión, un planeamiento pedagógico dirigido al uso de las TIC en la práctica docente. 
Palabras clave: Tecnologías de la Información y Comunicación; Enseñanza y aprendizaje; Matemática

\section{REFERÊNCIAS}

ALMEIDA, M. Prática e formação de professores na integração de mídias. In: Integração das tecnologias na educação. Secretaria de Educação a Distância. Brasília: Ministério da Educação, Seed, 2005.

ARAÚJO, R. S. de. Contribuições da metodologia WebQuest no processo de letramento dos alunos nas séries iniciais no ensino fundamental. In: MERCADO, Luís Paulo Leopoldo. (Org.). Vivências com aprendizagem na internet. Maceió: Edufal, 2005.

BALDIN, Yuriko Y. Uso de tecnologia como ferramenta didática no ensino integrado: uma forma de educação continuada para professores de nível básico. In: Carvalho, Luiz M. et al. História e tecnologia no ensino da matemática, Vol. 2. Rio de Janeiro: Editora Ciência Moderna Ltda., 2008.

BIANCHI, C. Educar: ensinar a pensar. Site Clube do Professor, 2003. Disponível em: <http://www.clubedoprofessor.com.br/artigos/Educar.htm>. Acesso em: outubro de 2011.

BICUDO, Maria Aparecida V. (Org.). Educação matemática. São Paulo: Editora Morais, 1987.

BORBA. M. de C.; PENTEADO M. G. Informática e educação matemática. Belo Horizonte: Autêntica, 2001.

BRASIL. Secretaria de Educação Fundamental. Parâmetros curriculares nacionais: introdução. Brasília: MEC/SEF, 1997a.

BRASIL. Secretaria da Educação Fundamental. Parâmetros Curriculares Nacionais: Matemática. Brasília: MEC/SEF, 1997 b.

CARTWRIGHT, Dorwing. Análisis del material cualitativo. In: FESTINGER, R. Z.; KATZ, D. Los métodos de investigación en ciencias sociales. México: Paidós, 1987.

CATTAI, A. P. Informática no ensino da matemática. Salvador: Editora FTC, 2007.

D’AMBROSIO, Ubiratan. Educação matemática: da teoria à prática. $9^{\text {a }}$ ed. Campinas: Papirus, 1996.

EVES, H. Introdução a história da matemática. Campinas: Editora da UNICAMP, 2004.

FIORENTINI, D; LORENZATO. S. Investigação em educação matemática: percursos teóricos e metodológicos. 2 ed. rev. Campinas: Autores Associados, 2007. 
LOPES, Antônio José. O uso inteligente das calculadoras no ensino fundamental. São Paulo: Câmara Brasileira do Livro. 1999. Disponível em: Http://cbl-net.com.br Acesso em: 03 de set. 2011.

LORENZATO, S. (Org.) O laboratório de ensino da matemática na formação dos professores. Campinas: Autores associados, 2006.

LÜDKE, M.; ANDRÉ. M. E. D. A. A pesquisa em educação, abordagens qualitativas. São Paulo: EPU, 1986.

MENDES, Iran Abreu. Matemática e investigação em sala de aula: tecendo redes cognitivas da aprendizagem. $2^{\text {a }}$ ed. São Paulo: Editora Livraria da Física, 2009.

SIVA, Ezequiel Theodoro da. Revalorização do livro diante das novas mídias. Veículos e linguagens do mundo contemporâneo: a educação do leitor para as encruzilhadas da mídia. In: 2005. Integração das tecnologias na educação. Brasília: Ministério da Educação, Seed,

SOARES, A; LOUREIRO, C.; VELOSO, M. G. Calculadora na educação matemática. Lisboa: APM, 1989.

TAHAN, Malba. Antologia da matemática, vol. 2. São Paulo: Saraiva, 1961. 